\title{
Characterization of Rockwell hardness indenter Tip using image processing and optical profiler and evaluation of measurement uncertainty
}

\author{
G. Moona ${ }^{\star}$, R. Sharma, D. Sharma, and V.N. Ojha \\ CSIR- National Physical Laboratory, Dr K.S. Krishnan Marg, 110012 New Delhi, India
}

Received: 30 January 2014 / Accepted: 12 September 2014

\begin{abstract}
Hardness is a measure of the resistance of a material to be penetrated and eroded by sharp projections of other materials such as diamond. The process of creating sharp projections on any test surface is known as indentation. Hardness measurement of any material is the result of a complex process of deformation during indentation. The indenter tip geometry, which includes radius of curvature at the tip and tip angle, affects the hardness measurement by influencing the nature of the penetration process on the test surface, because every indenter deforms the specimen surface with a different geometry. The controlled indenter geometry can improve the consistency of hardness measurement. In this paper we report the estimation of two important geometrical parameters, radius of curvature and tip angle of a Rockwell indenter by using a simple method of image processing and compare the results with those obtained with a traceable 3D optical profiler. Evaluation of uncertainty in measuremts is carried out as per ISO guidelines (ISO-GUM) and a detailed uncertainty budget is presented. The tip angle estimted is 119.95 degree. The radius of curvature is estimted to be $199.96 \pm 0.80 \mu \mathrm{m}$ by image analysis which agrees well with the value estimated by using optical profiler i.e. $199.12 \mu \mathrm{m}$.
\end{abstract}

Keywords: Indenter; radius os curvature; tip radius; image analysis; uncertainty

\section{Introduction}

The rapid development of structural materials and their successful applications in various sectors of industry have led to increasing demands for assessing their mechanical properties in small volumes. In the field of material science, to study the basic properties at smaller and smaller scales, different techniques are used to quantify material characteristics and tendencies. Measuring mechanical properties for materials at smaller scales can not be done using conventional tests like uniaxial tensile testing. As a result, techniques for testing material "hardness" by indenting a material with an impression have been developed. Hardness measurements quantify the resistance of a material to plastic deformation. Indentation hardness tests compose the majority of processes used to determine material hardness, and can be divided into two classes: microindentation and macroindentation tests. Microindentation tests typically have forces less than $2 \mathrm{~N}$ [1]. Hardness, however, cannot be considered to be a fundamental material property. Instead, it represents an arbitrary quantity used to provide a relative idea of material properties. As such, hardness can only offer a comparative idea of the

^Correspondence: moonag@mail.nplindia.org material's resistance to plastic deformation since different hardness techniques have different scales. Indentation hardness measures the resistance of a sample to material deformation due to a constant compression load from a sharp object and they are primarily used in engineering and metallurgy fields [2]. The process of creating sharp projections on any test surface is known as indentation. During the process of indentation the material under goes both compression and shear, resulting in the observed deformation, which comprises elastic deformation, flow and densification [3]. The tests work on the basic premise of measuring the critical dimensions of an indentation left by a specifically dimensioned and loaded indenter. If a very sharp tip is used, the volume of material that is tested can be made arbitrarily small [4]. Therefore in this case, it becomes very difficult to determine the indentation area. The hardness is in fact defined as the ratio between the maximum applied load $\left(P_{\max }\right)$ and the projected area of the indentation impression $\left(A_{\mathrm{p}}\right)$. Thus it is obvious that, changing the shape of the indenter (and in particular the tip angle and radius of curvature), the behaviour of the material penetration process changes resulting into the change in identification of material parameters [5].

In this paper, we work on the cone spherical/round end cone indenter and report the tip radius of curvature 

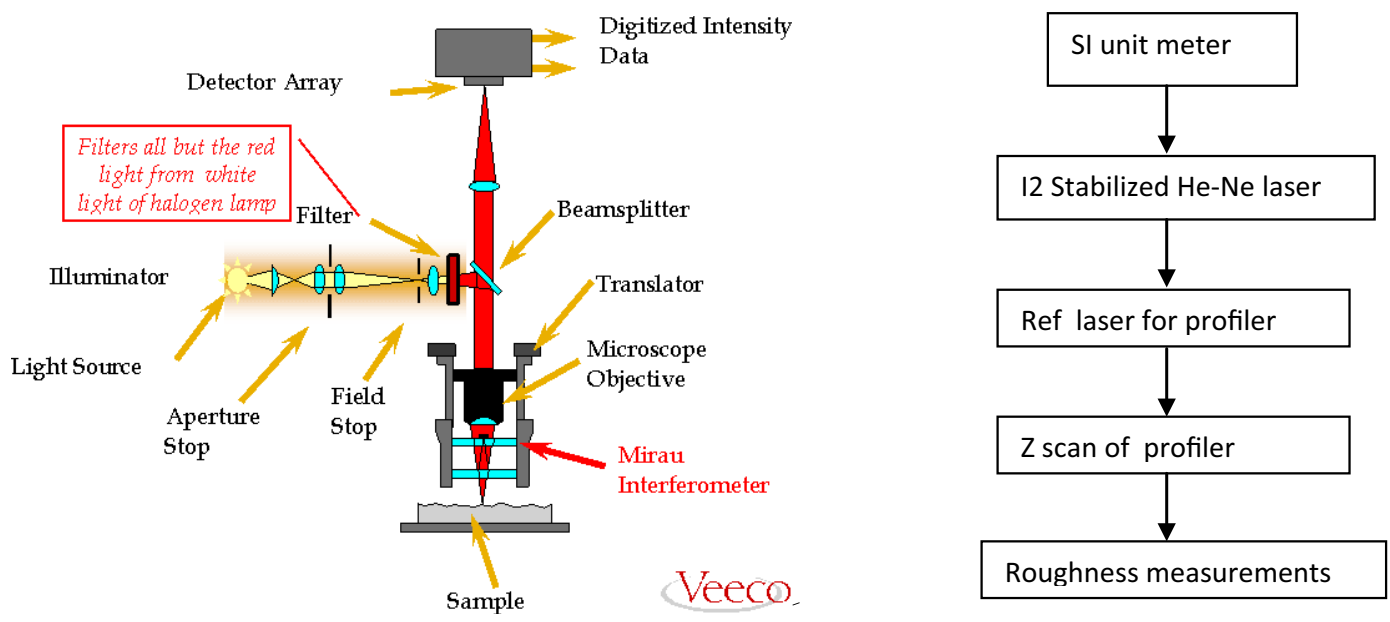

Fig. 1. Scheme of measurement in Optical Profiler and traceability chart.

and tip angle by a simple low cost using image processing method with software "Imagej" [6]. A traceable 3D non contact optical profiler is used to acquire image of the Rockwell hardness indenter tip We have also estimated and discussed measurement uncertainty according to ISOGuide to the expression of uncertainty in measurement

\section{Experimental setup}

The method comprises of two main steps, first is the image acquisition and second is the image analysis.

\subsection{Image acquisition}

In this simple method image of Rockwell harness indenter may be acquired by any optical microscope. Here we used microscope associated with a non contact 3D optical profiler (Model WYKO NT9800), in intensity mode (with help of a microscopic objective and CCD camera). When the optical profiler is used in intensity mode, it works as microscope. Ray diagram for microscope and traceability chart for optical proflier is given in Figure 1 [7]. The image was taken at 5.5X magnification (10X microscopic magnification objective and 0.55 field of view). To acquire image, microscopic objective is focused on tip of indenter and we get circular fringes. The top of tip is located by adjusting focus till we get smallest circular fringe in focus.

\subsection{Image analysis}

The intensity mode image of indenter tip taken by using optical profiler is then analyzed by image processing software "imagej". Further to validate the results we analysed the image by using $2 \mathrm{D}$ profile analyses in optical profiler software, WYKO Vision 4.20.1.0 The indenter tip angle was found out by taking the image of the indenter tip and extending lines on the two arms by using tool * straight* and making the cone angle and using *angle tool* in measurement option in "imagej" (Fig. 2).

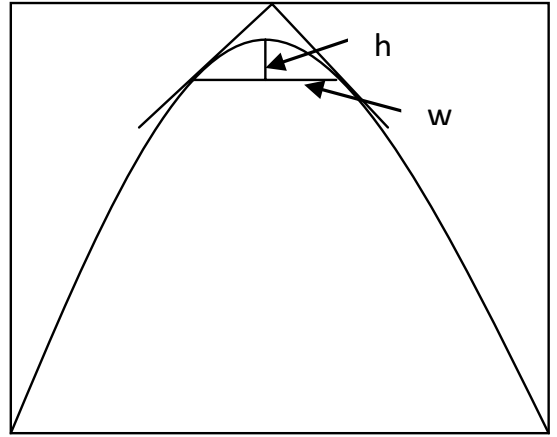

Fig. 2. Scheme of measurement in 'imagej'.

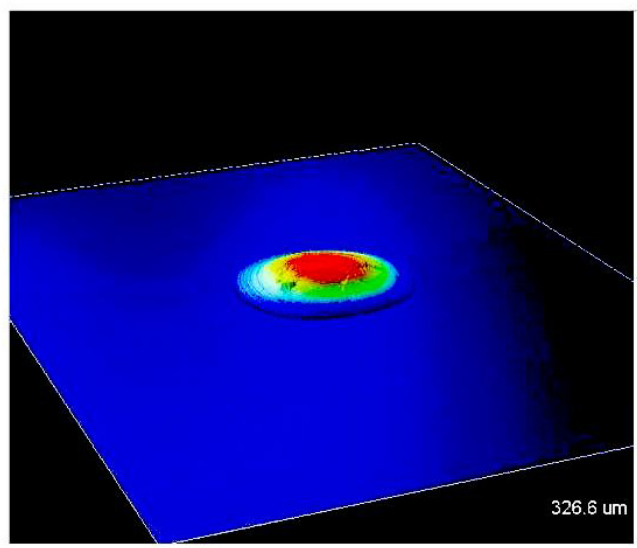

Fig. 3. Three dimensional opticalVSI image of indenter tip.

Radius of curvature was obtained by analysing the intensity image taken by optical profiler in "imagej" (Fig. 3) and then calculations are done by using equation (1):

Radius of curvature of the tip

$$
R=\frac{h^{2}+(w / 2)^{2}}{2 h} \text {. }
$$

Here: $h=$ depth of indentation and $w=$ base. 
Table 1. Image processing results for tip angle, using software 'imagej'.

\begin{tabular}{ccccc}
\hline $\begin{array}{c}\text { Sl } \\
\text { No }\end{array}$ & $\begin{array}{c}\text { Tip angle } \\
\text { in degree }\end{array}$ & $\begin{array}{c}w \\
(\mathrm{~mm})\end{array}$ & $\begin{array}{c}h \\
(\mathrm{~mm})\end{array}$ & $\begin{array}{c}R \text { \{calculated by using } \\
\text { equation }(2)\} \mu \mathrm{m}\end{array}$ \\
\hline 1 & 119.773 & 0.147 & 0.014 & 199.93 \\
2 & 120.496 & 0.146 & 0.014 & 197.32 \\
3 & 119.764 & 0.148 & 0.014 & 202.57 \\
4 & 119.773 & 0.152 & 0.015 & 200.03 \\
& Mean $=119.95$ & & & Mean $=199.96$ \\
\hline
\end{tabular}

\subsection{Validation of results using optical profiler}

For validation study, a 3 dimensional image of Rockwell hardness indenter tip was taken by using 3 D Optical profiler, with WYKO Vision 4.20.1.0 software in VSI (Vertical Scanning Interferometry) mode. This optical profiler is equipped with a He-Ne (633 nm) laser interferometer for nonlinearity correction and this interferometer provides direct traceability to SI unit [8]. The image for measurement is taken with optical profiler using Vertical scanning white light interferometry. In VSI mode, the white-light source is filtered with a neutral density filter, which preserves the short coherence length of the white light, and the system measures the degree of fringe modulation, or coherence, instead of the phase of the interference fringes. The irradiance signal is sampled at fixed intervals as the optical path difference (OPD) is varied by a continuous translation of the vertical axis through focus. Then system scans through focus (starting above focus) as the camera captures frames of interference data at evenly-spaced intervals. As the system scans downward, an interference signal for each point on the surface is recorded. The system uses a series of advanced computer algorithms to demodulate the envelope of the fringe signal. Finally the vertical position corresponding to the peak of the interference signal is extracted for each point on the surface and the imaging lens images the interferogram onto the CCD camera [9].

The values of $\mathrm{w}$ and $\mathrm{h}$ were taken from these profiles and equation (1) was again applied for estimating radius of curvature.

\section{Result and discussions}

The image acquired using $3 \mathrm{D}$ optical profiler, in intensity mode at $5.5 \times$ magnification objective is shown in Figure 3 . The tip angle is obtained by using image processing software imagej (Fig. 4). Radius of curvature is estimated by using Figure 2, Figure 4, imagej, and equation (1)

The image processing results are given in Table 1.

The validation of results obtained from image processing of acquired image (Fig. 3$)$ is done by using $2 \mathrm{D}(X \&$ $Y$ profiles of the indenter tip) profile option in WYKO Vision 4.20.1.0 software as shown in Figure 6.

The results obtained for radius of curvature from both the methods have been given in Table 2 .

These results of the radius of curvature obtained from image processing have been compared with those obtained

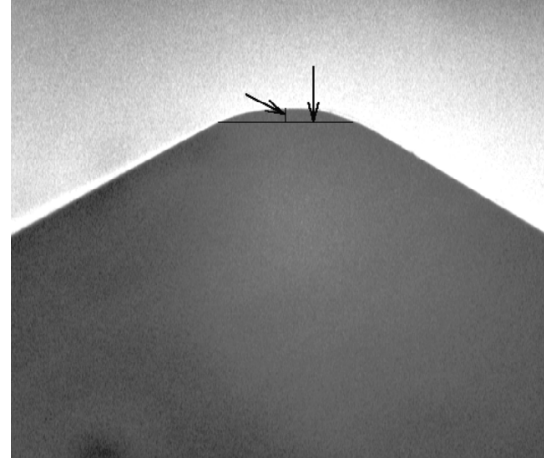

Fig. 4. Indenter imagetaken by using optical profiler.

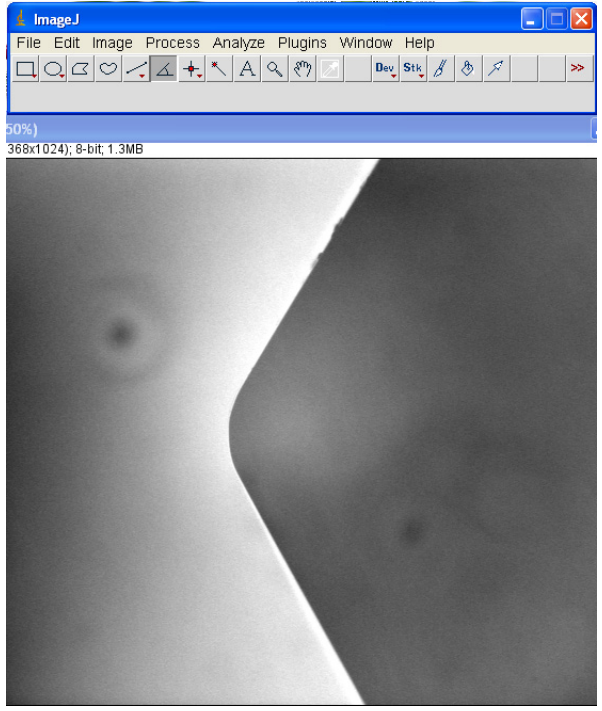

Fig. 5. Imagej window with indenter tip image.

from optical profiler measurements and it is observed that there is a good agreement between the two adopted techniques.

\section{Evaluation of uncertainty in measurements}

Measurement uncertainty analysis for our experiment is done as per ISO- Guide to the expression of uncertainty in measurement $[10,11]$.

Radius of curvature for indenter tip of Rockwell hardness indenter can be evaluated by using equation:

$$
R=\frac{h^{2}+(w / 2)^{2}}{2 h} .
$$


Table 2. Radius of curvature results.

\begin{tabular}{|c|c|c|c|c|c|}
\hline \multicolumn{3}{|c|}{$\begin{array}{l}\text { Optical profiler results } \\
\text { using software 'vision' }\end{array}$} & \multicolumn{3}{|c|}{$\begin{array}{l}\text { Image processing results } \\
\text { using software 'imagej' }\end{array}$} \\
\hline $\begin{array}{c}w / 2 \\
(y \text { profile }) \\
\mu \mathrm{m}\end{array}$ & $\begin{array}{c}h \\
\mu \mathrm{m}\end{array}$ & $\begin{array}{c}R \text { \{calculated } \\
\text { by using } \\
\text { equation }(2)\}\end{array}$ & $\begin{array}{c}w \\
(\mathrm{~mm}) \\
\mu \mathrm{m}\end{array}$ & $\begin{array}{c}h \\
(\mathrm{~mm})\end{array}$ & $\begin{array}{c}R\{\text { calculated by } \\
\text { using equation }(2)\} \\
\mu \mathrm{m}\end{array}$ \\
\hline 56.1 & 8.1 & 198.32 & 0.147 & 0.014 & 199.93 \\
\hline 57.1 & 8.4 & 198.27 & 0.146 & 0.014 & 197.32 \\
\hline 57.02 & 8.3 & 199.87 & 0.148 & 0.014 & 202.57 \\
\hline 57.02 & 8.3 & $\begin{array}{c}200.01 \\
\text { Mean }=199.12\end{array}$ & 0.152 & 0.015 & $\begin{array}{c}200.03 \\
\text { Mean }=199.96\end{array}$ \\
\hline
\end{tabular}

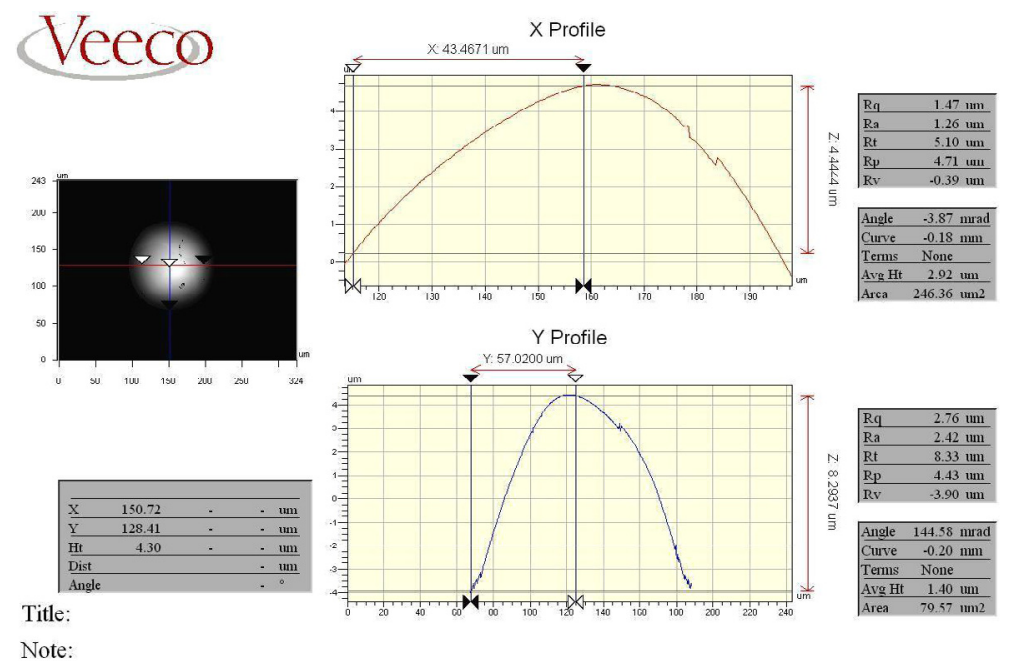

This is the main model function, which can further be simplified as:

$$
R=\frac{h^{2}}{2 h}+\frac{0.5 w^{2}}{2 h}=0.5 h+0.125 w^{2} h^{-1}
$$

Sensitivity coefficients for the above will be as given below:

$$
\begin{gathered}
C_{h}=\frac{\delta R}{\delta h}=0.5-0.125 w^{2} h^{-2} . \\
C_{w}=\frac{\delta R}{\delta w}=0.25 w h^{-1} .
\end{gathered}
$$

The submodel function for measurement of $h$ and $w$ will be same and is given by following equation:

$$
E=M . V .-A . V .+\delta_{T}+\delta_{T S}+\delta_{\alpha}+\delta_{X Y}+\delta_{I}+\delta_{I P},
$$

where,

$$
\begin{aligned}
E= & \text { error; } \\
M . V .= & \text { measured value; } \\
A . V .= & \text { actual value; } \\
\delta_{T}= & \text { correction due to temperature variation } \\
& \text { during measurement; } \\
\delta_{T S}= & \text { correction due to uncertainty of } \\
& \text { temperature sensor; } \\
\delta_{\alpha}= & \text { Correction due to variation in thermal } \\
& \text { coefficient of expansion; }
\end{aligned}
$$

$\delta_{X Y}=$ correction due to resolution of optical profiler in $x y$ profile;
Fig. 6. Scheme of $X$ and $Y$ profiles of the indenter tip using optical profiler in VSI mode.

$\delta_{I}=$ correction due to resolution of optical profiler in intensity mode;

$\delta_{I P}=$ correction due to resolution in image processing while doing edge detection.

\subsection{Contribution due to temperature variation during measurement $\left(\delta_{\mathrm{T}}\right)$}

Limit value: \pm 0.1 .

Distribution: rectangular, Type B.

Standard uncertainty $=0.05 / \sqrt{ } 3=0.03$.

Sensitivity coefficient for this will be $\frac{\delta T}{T}=h \alpha=1 \mu \mathrm{m}$.

\subsection{Contribution due to uncertainty of temperature sensor $\left(\delta_{\mathrm{TS}}\right)$}

Certificate value: $\pm 0.03(k=1)$.

Distribution: normal, Type B.

Standard uncertainty $=0.03$.

Sensitivity coefficient for this will be $\frac{\delta T s}{T}=h \alpha=$ $1 \mu \mathrm{m}$.

\subsection{Contribution due to variation in thermal coefficient of expansion $\left(\delta_{\alpha}\right)$}

Limit value: $\pm 10 \%$ of $\alpha$. 
Table 3. Detailed uncertainty budget for $h$ and $w$ measurements.

\begin{tabular}{|c|c|c|c|c|c|c|c|}
\hline $\begin{array}{l}\text { Source of uncertainty for } \\
\text { ' } h \text { ' measurements }\end{array}$ & $\begin{array}{c}\text { Limit } \\
( \pm)\end{array}$ & Type & Distribution & DOF & $\begin{array}{c}\text { Standard } \\
\text { uncertainty }\end{array}$ & $\begin{array}{l}\text { Sensitivity } \\
\text { coefficient }\end{array}$ & $\begin{array}{c}\text { Uncertainty } \\
\text { contribution } u_{i}(\mu \mathrm{m})\end{array}$ \\
\hline $\begin{array}{l}\text { Deviation of } \\
\text { temperature }\end{array}$ & 0.05 & B & $\mathrm{R}$ & $\infty$ & 0.03 & 1 & 0.03 \\
\hline $\begin{array}{c}\text { Uncertainty of } \\
\text { temperature sensor }\end{array}$ & 0.06 & B & $\mathrm{N}$ & $\infty$ & 0.03 & 1 & 0.03 \\
\hline $\begin{array}{l}\text { Deviation of thermal } \\
\text { coefficient of expansion }\end{array}$ & 0.05 & B & $\mathrm{R}$ & $\infty$ & 0.03 & 0.1 & 0.003 \\
\hline Image resolution & 1.29 & B & $\mathrm{R}$ & $\infty$ & 0.74 & 1 & 0.74 \\
\hline $\begin{array}{l}\text { Resolution of profiler } \\
\text { in intensity mode }\end{array}$ & 0.59 & B & $\mathrm{R}$ & $\infty$ & 0.34 & 1 & 0.34 \\
\hline $\begin{array}{l}\text { Resolution in image } \\
\text { processing while } \\
\text { doing edge detection }\end{array}$ & 0.5 & B & $\mathrm{R}$ & $\infty$ & 0.29 & 1 & 0.29 \\
\hline Repeatability $h$ & - & $\mathrm{A}$ & $\mathrm{N}$ & 4 & 0.054 & 1 & 0.054 \\
\hline
\end{tabular}

Combined uncertainty of $h=0.87 \mu \mathrm{m}$. Expanded uncertainty $(k=2)=1.74 \mu \mathrm{m}$.

\begin{tabular}{|c|c|c|c|c|c|c|c|}
\hline $\begin{array}{l}\text { Source of uncertainty for } \\
\text { " } w \text { " measurements }\end{array}$ & $\begin{array}{c}\text { Limit } \\
( \pm)\end{array}$ & Type & Distribution & $\mathrm{DOF}$ & $\begin{array}{c}\text { Standard } \\
\text { uncertainty }\end{array}$ & $\begin{array}{l}\text { Sensitivity } \\
\text { coefficient }\end{array}$ & $\begin{array}{c}\text { Uncertainty } \\
\text { contribution } u_{i}(\mu \mathrm{m})\end{array}$ \\
\hline Deviation of temperature & 0.05 & $\mathrm{~B}$ & $\mathrm{R}$ & $\infty$ & 0.03 & 1 & 0.03 \\
\hline $\begin{array}{c}\text { Uncertainty of } \\
\text { temperature sensor }\end{array}$ & 0.06 & B & $\mathrm{N}$ & $\infty$ & 0.03 & 1 & 0.03 \\
\hline $\begin{array}{l}\text { Deviation of thermal } \\
\text { coefficient of expansion }\end{array}$ & 0.05 & $\mathrm{~B}$ & $\mathrm{R}$ & $\infty$ & 0.03 & 0.1 & 0.003 \\
\hline Image resolution & 1.29 & $\mathrm{~B}$ & $\mathrm{R}$ & $\infty$ & 0.74 & 1 & 0.74 \\
\hline $\begin{array}{l}\text { Resolution of profiler } \\
\text { in intensity mode }\end{array}$ & 0.59 & $\mathrm{~B}$ & $\mathrm{R}$ & $\infty$ & 0.34 & 1 & 0.34 \\
\hline $\begin{array}{l}\text { Resolution in image } \\
\text { processing while } \\
\text { doing edge detection }\end{array}$ & 0.5 & B & $\mathrm{R}$ & $\infty$ & 0.29 & 1 & 0.29 \\
\hline Repeatability $w$ & - & $\mathrm{A}$ & $\mathrm{N}$ & 4 & 0.19 & 1 & 0.19 \\
\hline
\end{tabular}

Combined uncertainty of $w=0.87 \mu \mathrm{m}$. Expanded uncertainty $(k=2)=1.74 \mu \mathrm{m}$.

(Thermal coefficient of expansion for diamond cone Rockwell hardness indenter is $1 \times 10^{-6} / \mathrm{K}$.)

Distribution: rectangular, Type B.

Standard uncertainty $=0.05 / \sqrt{ } 3=0.03$.

Sensitivity coefficient for this will be $\frac{\delta \alpha}{\alpha}=h T=$ $0.1 \mu \mathrm{m}$.

\subsection{Contribution due to resolution of optical profiler in $\mathrm{xy}$ profile $\left(\delta_{\mathrm{XY}}\right)$}

Limit value: $\pm 2.58 \mu \mathrm{m}$ per pixel.

Distribution: rectangular, Type B.

Standard uncertainty $=1.29 / \sqrt{ } 3=0.74$.

Sensitivity coefficient for this will be $=1$ pixel.

\subsection{Contribution due to resolution of optical profiler in intensity mode $\left(\delta_{1}\right)$}

Limit value: $\pm 1.18 \mu \mathrm{m}$ per pixel.

Distribution: rectangular, Type B.

Standard uncertainty $=0.59 / \sqrt{ } 3=0.34$.

Sensitivity coefficient for this will be $=1$ pixel.

\subsection{Contribution due to resolution in image processing while doing edge detection $\left(\delta_{\mathrm{IP}}\right)$}

Limit value: $\pm 1 \mu \mathrm{m}$.

Distribution: rectangular, Type B.

Standard uncertainty $=0.5 / \sqrt{ } 3=0.29$.

Sensitivity coefficient for this will be $=1 \mu \mathrm{m}$.

\subsection{Contribution from measured value repeatability}

The repeatability was calculated by using measured values and type A uncertainty calculation.

Type A uncertainty $=\frac{s}{\sqrt{n}}$, where $s$ is the standard deviation and $n$ is number of observations. The standard deviation is expressed as

$$
s=\sqrt{\frac{\sum_{j=1}^{n}\left(x_{j}-x_{\text {mean }}\right)^{2}}{n-1} .}
$$

The detailed uncertainty budget for $h$ and $w$ measurements is given in Table 3 . 
Table 4. Detailed uncertainty budget for radius of curvature measurements.

\begin{tabular}{cccccccc}
\hline $\begin{array}{c}\text { Source of uncertainty } \\
\text { for ' } R \text { ' measurements }\end{array}$ & $\begin{array}{c}\text { Limit } \\
( \pm)\end{array}$ & Type & Distribution & DOF & $\begin{array}{c}\text { Standard } \\
\text { uncertainty }\end{array}$ & $\begin{array}{c}\text { Sensitivity } \\
\text { coefficient }\end{array}$ & $\begin{array}{c}\text { Uncertainty } \\
\text { contribution } u_{i}(\mu \mathrm{m})\end{array}$ \\
\hline Depth of indentation $(h)$ & 1.74 & $\mathrm{~B}$ & $\mathrm{~N}$ & $\infty$ & 0.87 & 0.375 & 0.33 \\
Base $(w)$ & 1.74 & $\mathrm{~B}$ & $\mathrm{~N}$ & $\infty$ & 0.87 & 0.25 & 0.22 \\
\hline
\end{tabular}

The uncertainty budget for radius of curvature measurements $R$ is given in Table 4 .

Effective degree of freedom $V_{\text {eff }}[10,11]$ :

$$
V_{\text {eff }}=\frac{u^{4}(y)}{\sum_{i=1}^{N} \frac{u_{i}^{4}(y)}{v_{i}}}=178183.8
$$

Combined uncertainty $=0.40 \mu \mathrm{m}$.

Expanded uncertainty at $95.45 \%$ confidence level and $(k=2)$ is $=0.80 \mu \mathrm{m}$.

\section{Conclusions}

The radius of curvature and tip angle of an indenter tip can be very important in selecting the proper indenter to be used for a specific application. A good estimate of radius of curvature will also allow a user to get more repeatable data when changing hardness indenter tip.

The radius of curvature of indenter tip has been observed to be $199.96 \mu \mathrm{m}$ by image analysis and $199.12 \mu \mathrm{m}$ by optical method. Measurement uncertainty for radius of curvature is $\pm 0.80 \mu \mathrm{m}$ at $k=2$. Thus two estimates for radius of curvature of indenter tip from these two methods are within the uncertainty of measurements. The tip angle is coming out to be 119.95 .

Thus we conclude that image processing method can also be used to determine radius of curvature of a hardness indenter. The software "imagej" is available for free download from internet. It is very user friendly and very simple to work with. However there is a need to improve accuracy and reduce measurement uncertainty and this can be improved further by using edge enhancing methods along with image processing. This work can also be extended to conduct image analysis of AFM nanoindentation.

Acknowledgements. The authors are thankful to Prof. R.C. Budhani Director, NPL for his constant support and encouragement. We are also thankful to "Department of electronics and information technology" (DeitY), Ministry of information technology, India for funding the nanometrology project under which traceable optical profiler was established. We are also thankful to Dr. S.S.K. Titus for providing us the Rockwell indenter.

\section{References}

1. L. Calabri, N. Pungo, C. Mennozzi, S. valeri, AFM nanoindentation: tip shape and tip radius of curvature effect on hardness measurements, J. Phys. Condens. Matter 20, 474208 (2008)

2. X. Li, B. Bhushan, A review of nanoindentation continuous stiffness measurement technique and its applications, Mater. Charact. 48, 11-36 (2002)

3. H.O. Neill, Hardness and Hardness measurements, 2nd edition (Chapman and Hall, 1967)

4. W.C. Oliver, G.M. Pharr, An improved technique for determining hardness and elastic modulus using load and displacement sensing indentation experiments, J. Mater. Res. 7, 1564-1583 (1992)

5. D. Durban, R. Masri, Conical indentation of strainhardening solids, Eur. J. Mech. - A/Solids 27, 210-221 (2008)

6. http://imagej.en.softonic.com

7. https://cmi.epfl.ch/metrology/Wyko_NT1100.php (2014)

8. M. Chand, A. Mehta, R. Sharma, V.N. Ojha, K.P. Chaudhary, Roughness measurement using optical profiler with self reference laser and stylus instrument - A comparative study, Indian J. Pure Appl. Phys. 49, 335-339 (2011)

9. NT-9800 setup and operation guide

10. www.bipm.org/utils/common/documents/jcgm/JCGM 101_2008_E.pdf (2014)

11. V.N. Ojha, Evaluation \& expression of uncertainty of measurements, MAPAN J. Metrol. Soc. India 13, 71-84 (1998) 